\title{
ENTREVISTA COM O PROFESSOR ALFREDO WAGNER ALMEIDA
}

WIDNEY P. LIMA

UFRGS

JOÃO D. D. RAMOS

UFRGS

CRISTHIANO K. DA. SILVA

UFRGS

Durante a realização do evento de abertura do ano acadêmico do Programa de Pós-Graduação em Antropologia Social da Universidade Federal do Rio Grande do Sul, em março de 2012, tivemos a oportunidade de conversar com o professor Alfredo Wagner Berno de Almeida. Esta entrevista se deu após uma das mesas redondas do Evento, intitulada "Territorialidades Tradicionais e Direitos Coletivos", que contou com a participação, além de Alfredo, de Bira, militante do movimento negro, ligado ao IACOREQ (Instituto de Apoio às Comunidades Remanescentes Quilombolas), de Miriam Chagas, antropóloga ligada ao Ministério Público Federal (RS), e do professor da UFRGS José Otávio Catafesto de Souza.

Um dos aspectos mais importantes da realização desta mesa redonda (coordenada pela professora da UFRGS Denise Jardim) foi a questão da territorialidade e das mudanças semânticas ligadas ao conceito de território. Conforme veremos na entrevista, Alfredo Wagner pondera que há uma novidade em relação aos estudos e conceituações em torno do território que passam pelos trabalhos tanto de Michel Foucault quanto de Pierre Bourdieu, que apresentam a questão da segurança entrelaçada com a questão do território. Conforme Alfredo, há, também, uma mudança da maneira como as comunidades tradicionais acabam usando o sentido de território. 
O que se passa, portanto, é a "dessemantização" do termo território: estamos diante de novas formas e novos modos de articular politicamente a noção, além do modo de vida das comunidades e a atuação do Estado neste sentido. Este último tenta uma reapropriação da categoria território e enquadra o que é e o que pode ser tomado enquanto "território tradicional". Acaba-se focando, deste modo, numa flexibilização do direito territorial, onde o grupo tradicional se vê na situação de aceitar uma parte do território do que não ter o direito. Nesta fragmentação do espaço vivido, o grupo passa a operar novos modos de conceber seus territórios, levando adiante, certamente, novos modos de como ele é ocupado, vivido e concebido.

Num outro escopo, Alfredo aponta as implicações que as comunidades e o Estado operam em relação ao território que podem atingir o modo de conceitualização que a Antropologia dá ao termo. Afirmando que estamos diante de um repensar da Antropologia, Alfredo retoma alguns elementos que poderiam aproximar os conhecimentos nativos e do/a etnógrafo/a no mesmo plano, sendo crucial tomar as definições e a consciência de necessidade que o grupo tradicional aponta.

Durante as reuniões realizadas para pensarmos o evento, um dos tópicos abordados estava vinculado a quem seriam as pessoas convidadas a proferir falas que abordassem a temática central da proposta e, também, que viessem pensando formas de atividades que estivessem sendo empregadas em algumas áreas do Brasil. O nome do professor Alfredo Wagner veio de imediato, já que sua atuação junto ao Projeto Nova Cartografia Social da Amazônia (PNCSA) nos pareceu altamente relevante, justamente pelo fato dele e o projeto abordarem a questão do território e suas nuanças conceituais.

Para ele trata-se atualmente não de reafirmamento dos conceitos ora empregados em torno do termo território, mas da desconstrução desses conceitos. Para tanto, trabalha com dois pontos cruciais, que são a questão da proteção e do protecionismo, que convergem mais adiante na noção de necessidades e de quem tem o direito de explicitar estas necessidades. Alfredo Wagner aponta que a proteção tinha força por reconhecer a existência das minorias; e o protecionismo, a partir da abertura comercial, coloca o Estado brasileiro num embate tenso onde o 
choque de interesses se desdobra pela defesa comercial chegando à questão territorial entre os povos tradicionais. Sendo assim, Alfredo Wagner enxerga o sistema de proteção enquanto aquele que protegia as minorias, mesmo de forma precária, e o protecionismo como o modelo que abre as portas para a especulação, principalmente a territorial, mas, também, na questão dos conhecimentos tradicionais.

Tudo isso aponta a questão da necessidade, que está atrelada aos termos tratados no parágrafo anterior. Um forte questionamento que ele faz é: Quem é que define a necessidade dos outros? De onde emana a consciência da necessidade? Tal discussão está estreitamente vinculada ao PNCSA, já que a resposta que poderia ser dada a essas perguntas obviamente seria a de que a definição e o local de onde surgem as demandas por necessidade deveriam ser consideradas a partir das minorias, dos povos tradicionais. Então, neste sentido, o projeto ativa novas maneiras de pensar e negociar o território fazendo com que a ação protecionista não alcance seu objetivo principal, que é a supressão das identidades das minorias.

João: Bom, professor, a princípio, como tínhamos falado de forma breve, a ideia seria de aproveitar o momento que você veio para o evento e fazer uma pequena entrevista, conversar algumas ideias e daí, depois, pedir autorização para uma possível publicação. Temos algumas revistas no programa, revistas eletrônicas, Revista Horizontes Antropológicos e a Espaço Ameríndio, para que você conheça e aí depois fazermos uma espécie de publicação dessa conversa. Eu elenquei algumas questões que você estava falando na mesa agora, mas o Widney também tem algumas outras questões. Caso ele queira iniciar perguntando sobre o Projeto Nova Cartografia Social da Amazônia (PNCSA), depois vamos encaminhando com outras questões.

Widney: O que nos fez convidá-lo a participar do evento foi muito mais o vínculo e o teu protagonismo junto ao PNCSA. As duas perguntas principais que eu queria fazer são: 1) O que é o Projeto Nova Cartografia 
Social na Amazônia e 2) Qual o nível de atuação desse projeto junto as populações indígenas e tradicionais na Amazônia, local onde você trabalha e onde desenvolve suas atividades?

Alfredo Wagner: Benedict Anderson, em Comunidades Imaginadas, assevera que na constituição de uma sociedade nacional há três instituições que aparecem como definidoras de uma identidade legítima: o mapa, o senso e o museu. O mapa sempre foi um instrumento de poder, sempre foi uma forma de manter a dominação em sociedades coloniais e imperiais. Quando se fez importante uma representação gráfica para expressar uma dominialidade, os mapas foram ressaltados. Quem era capaz de mapear o outro, o que foi muito característico da sociedade colonial, era aquele que tinha condição de se impor. Produzir mapa foi, no início, uma atividade militar. 0 colégio dos cartógrafos de Borges, citado por Bourdieu, Baudrillard e Foucault, era um colégio de militares, que traçava estratégias e delineava formas de atuação, que descreviam maneiras de conquistar e de dominar. A própria geografia era uma ciência militar, uma ciência da guerra e uma ciência militar. A cartografia também. A cartografia se desenvolve deste modo. Assim, para as nações, quem faz o mapa, são as forças armadas. $O$ exército faz o mapa, seja aqui, seja na Alemanha. Nós chegamos a constatar a relevância desses mapas. Na Segunda Guerra Mundial, este instrumento foi consagrado, foi levado ao extremo. Todas as discussões levavam aos mapas. Em $O$ grande ditador Chaplin chega a fazer uma ironia, girando um globo terrestre às vistas de Hitler e de Mussolini, ambos disputando quem sentaria numa cadeira mais alta para se sobrepor ao outro. Com aquela ideia de mostrar um mapa no fundo da cena, torna-se evidente que a relevância não era mais o mundo, senão a representação cartográfica do que era o mundo. Esta importância do mapa se agigantou muito no caso brasileiro a partir da ditadura instituída a partir do golpe militar de 1964. Para o conhecimento cartográfico sistemático da Amazônia, o governo militar começou com o projeto RADAM, em 1972. Consistia numa expressão militar da forma de ocupação que o governo autoritário naquele momento imaginava que era possível. Privilegiava-se, então, o conhecimento do subsolo, dos recursos geológicos. A cartografia foi vista como uma ciência ligada a geógrafos, 
a geólogos e a engenheiros florestais. Foi sempre uma ciência pensada no âmbito das ciências naturais. Mais recentemente, quando nos anos 80 começamos a pensar numa forma de contestar, uma forma de você fazer o mapa do ponto de vista de quem estava sendo dominado, porque eles não tinham o poder de cartografar, eclodiram conflitos. $O$ primeiro trabalho que nós concebemos, foi um trabalho que foi feito durante quatro anos, em mais de 150 comunidades, envolvendo múltiplas pessoas, por isso que eu falo no plural, não é uma proposição minha, a discussão e a execução envolveram muitos pesquisadores. Contribuí e aprendi muito. Nós, da equipe de cientistas sociais, fizemos um mapeamento completo na "região do Carajás", que era uma região que compreendia 90 milhões de hectares. Abrangia desde as minas, com incidência de minerais, ferro e ouro, as grandes plantações de eucalipto, as usinas de gusa. Até o porto, são 980 quilômetros desde as minas, até o porto de Itaqui. O resultado deste amplo trabalho coletivo foi o livro que me coube redigir, narrando a experiência, intitulado $A$ Guerra dos Mapas. Foi a primeira experiência de maior fôlego, pois até então só havia produzido mapas a partir de informações secundárias ou simplesmente assinalando pontos de observação direta realizado durante trabalho de campo. O nome do livro, de certa forma, consagrou esse tipo de perspectiva, anunciando um conflito ainda de uma maneira muito incipiente, muito embrionária. Nós fomos aperfeiçoando os procedimentos, avançando em relações de pesquisa mais profícuas. Primeiro, levantamos os conflitos nessas áreas, mais de um mil assassinatos de indígenas e trabalhadores rurais, indicando inclusive nomes de executores e mandantes, tais como divulgados pelas entidades confessionais e associações voluntárias da sociedade civil. Até então éramos nós que concebíamos os mapas e só colocávamos na base o que achávamos relevante. Era um trabalho feito de certa maneira de fora, um trabalho de outsiders. Aquela viagem em que você utiliza técnicas de observação direta e aprofunda as relações de entrevista, mas sempre num patamar de mediação.

Neste processo de produção cartográfica havia interação, muita discussão e discordâncias superficiais. Havia agentes sociais narrando as rotas, o que passou a nos conduzir ao procedimento de levar em conta o que as pessoas falavam. Uma rota imensa e mais acidentes que 
eles pediram que colocássemos no mapa. Tudo isto sem erros maiores, mas ainda éramos nós que estávamos detendo a prerrogativa de mapear. E perguntas se colocavam: quem é o sujeito dessa ação? Então os próprios pesquisadores redefiniram seu trabalho. Iniciei a redefinição de minha postura. Posteriormente a isso, nós executamos um trabalho na llha de Marajó também, com outra equipe, em 1995 e 1996. Foi se consolidando essa importância de produzir um mapeamento social, e aqui já começamos a produzir distinções, não era mais geografia, não era mais o terreno, não era a paisagem, não eram os fatores ambientais. O produto final qual era? Íamos mapear o quê? O que era o mapeamento social? Era o produto das relações que nós estávamos estabelecendo naquele campo de disputas e de onde as pessoas iam definindo seus domínios, os seus pertencimentos e as suas reivindicações de direitos territoriais. Não era um parecer técnico, eram dados de pesquisa que poderiam servir até para justificar a defesa, nos conflitos, nas ações, nas disputas jurídicas. Executamos o trabalho na Ilha de Marajó, com uma equipe de três antropólogos, uma agrônoma e uma geógrafa. Concluímos o levantamento em Santa Cruz e Cachoeira, uma região toda cercada por grandes fazendas desde o período pré-pombalino. Região de ocupação jesuíta, são as grandes fazendas jesuítas no Rio Arari. E nós então viemos trabalhando com esta redefinição de procedimento, mas já deixando que as certas lideranças assumissem a ideia do mapa. Isso acabou ganhando mais fôlego já em 2004, quando estava na coordenação do movimento interestadual das quebradeiras de coco-babaçú, quebradeiras de São José dos Mouras, que é um povoado do Maranhão. Dona Dada, ela nos convidou para produzir um mapeamento social das áreas em que as quebradeiras trabalhavam. Aí nós produzimos um outro livro, feito em coordenação partilhada com um advogado, Joaquim Shiraishi, e uma antropóloga, Cyntia Carvalho Martins. O livro recebeu o título de Guerra Ecológica nos Babaçuais. Então, entre o Guerra dos Mapas e o Guerra Ecológica dos Babaçuais se passaram alguns 13 anos, e nós fomos sedimentando essa prática de mapear. Entre estes dois livros havíamos feito uma experiência de mapeamento social em Belém, juntamente com Jurandir Novaes e Solange Gaioso. Formamos também uma rede de pesquisadores conjugada com uma rede de representantes dos movimentos sociais. 
ENTREVISTA COM O PROFESSOR ALFREDO WAGNER ALMEIDA

Uma rede de líderes que passou a interagir intensamente. Nós começamos a pensar a ideia dos fascículos. Um arquiteto e designer nos ajudou nesta tarefa: Ernandes Fernandes. Nós produzimos seis fascículos sobre as quebradeiras, uma réplica do Guerra Ecológica, mas os mapas eram feitos por terceiros. E discutimos e decidimos mudar isto trazendo o laboratório para dentro da equipe de pesquisa, fazendo os mapas e as legendas com o que os agentes sociais entrevistados consideravam relevante. Foi uma ruptura profunda. Até o momento produzimos 150 fascículos. Nos seis primeiros fascículos, nós não tínhamos tal ideia de mapeamento, consistiam numa reprodução do mapa grande, que nós tínhamos produzido, eram subprodutos localizados no mapa maior sobre as quebradeiras. E a partir daí nós começamos a pensar: como é que o grupo entrava nesse mapeamento social? Qual era a relevância da informação local e de quem a produzia? Só entrava no mapa aquilo que o grupo definia? Quem definia o mapa era o próprio grupo? Quem definia a escala era o próprio grupo? Então tudo passou a ser mais discutido e começou a escapar desse controle estrito do pesquisador de dizer qual é - porque o Estado faz isso. $O$ Estado produz o mapa, mas ele que diz a escala, se é 1:100, 1000:1000000, ele que diz qual é a escala e ele é que define o que entra no mapa. As oficinas de mapa consistem neste processo de discussão e produção cartográfica.

Então nós iniciamos esse processo em 2005 - 2007 e nós começamos a mudar um pouco o sentido. Nós começamos a ensinar também noções básicas de GPS e do software, que no caso é o ArqGiz. Então isso aí foi permitindo aos grupos não só (já tinham conhecimento de GPS) pegar e amarrar os pontos em área. Produzir, mas também já trabalhar o software, conseguir passar esses pontos para um computador que já, com software, uma base de desktop já definido. Então, aí, o que ocorre, o próprio grupo passou a produzir o gerenciamento ou o mapeamento da sua própria condição. E nós éramos apenas aqueles que ensinávamos os instrumentos analíticos para que o grupo pudesse se representar cartograficamente. Então nós ensinávamos: noções elementares de GPS, noções elementares de direito ambiental, noções elementares de direito agrário e sobre a Convenção 169, noções elementares de formas de organização política 
e o grupo ia definindo o que ele fazia com aquilo. Nós passamos a ministrar pequenos cursos. E a partir daí, os mapas foram ganhando mais densidade. Os ícones nós definíamos, inicialmente nós, e depois passamos a utilizar os ícones do próprio grupo, construindo as legendas. As cores, do mesmo modo: nós achávamos que os rios são sempre azuis, que as águas são azuis, mas para eles eram de cor marrom! Fomos trabalhando e modificando cores e legendas e tudo mais, nós aceleramos esse trabalho. $\mathrm{E}$ as oficinas de mapa passaram a ser o cerne do trabalho. Então, o PNCSA, na verdade, para responder a pergunta, ele passou a representar um conjunto de projetos com estes procedimentos. Há um projeto de mapeamento social que é Mapeamento Social da Panamazônia, que é financiado pela Fundação Ford. Há outro projeto de mapeamento social na consolidação do Instituto de Cartografia Social, que é também financiado pela Fundação Ford. Há um projeto de mapeamento social que é de mobilização contra devastação e desmatamento, que está no âmbito do Fundo Amazônia, que é administrado pelo BNDES. Tem outro trabalho de cartografias antropológicas que é financiado no âmbito da própria UEA. Então nós ficamos com quatro projetos, que correspondem atualmente ao nosso desenho, são quatro grandes projetos. Esses projetos relativizam a ideia de biodiversidade, afirmando uma sociodiversidade. E trabalham com povos indígenas, quilombolas, pescadores, ribeirinhos, quebradeiras de coco-babaçu, piaçadeiros, peconheiros, mulheres artesãs, pescadores artesanais. Trata-se de um elenco muito grande de todas essas identidades emergentes hoje na Amazônia. E nós acabamos, com esse trabalho, conseguindo chamar a atenção para a política nacional de desenvolvimento sustentável de povos e comunidades tradicionais. Porque o Brasil, a partir de 2003, ratifica a Convenção 169, e nós começamos a trabalhar com esses povos e comunidades tradicionais que equivaleria a uma situação idealizada de povos e populações tribais da 169. Ao fazer isso, nós lidamos de duas maneiras evitando uma ação sem sujeito. Não era uma ação sem sujeito. Essa ação sempre teve sujeito. E quem era o sujeito dessa ação? Então o sujeito da ação pode variar. São todas as pessoas que assinam e comparecem às oficinas. Produzem o "mapa da comunidade", tal como expresso por essas pessoas que compareceram nas oficinas, e são elas que dizem qual a 
representação cartográfica da comunidade. Então, não é uma ação sem sujeito. Todos assinam o mapa. Ao elencar essas pessoas, procuramos evitar que ocorra qualquer personificação do coletivo. Não há isso, porque essas pessoas são todas nomeadas, você abre e está dizendo quem participou das oficinas. "Dia tal: fulano, fulano, fulano". "Dia tal: beltrano, beltrano e beltrano". Há uma reunião de consulta em Alcântara (MA) que tem 500 pessoas que participaram. E está o nome das quinhentas pessoas no fascículo. Então, esse desafio está sendo superado, e não sei se estou sendo fiel a tua pergunta? Esse desafio que nós vamos, digamos assim, nós vamos colocando nesse quadro da equipe, nós vamos colocando todos os que participaram da oficina. Há equipe de facilitadores e membros da própria comunidade pesquisada, cartografada. Então esse aí foi um outro ponto central do nosso trabalho. Não incorrer na personificação do coletivo e não ter uma ação sem sujeito. Uma personificação do coletivo é dizer assim: "Os proletários", "os não sei o que". Não, não tem isso! Você diz quem é, onde é, que comunidade é essa, os nomes são estes. Se houver uma outra informação é essa, que fez isso e que fala assim, então você tem um sistema de citação. Então nós pensamos dentro desse projeto: fascículos, boletins informativos, mapas situacionais e livros que têm uma periodicidade mais ou menos regular, que funciona como se fosse um periódico, um boletim informativo, mas ele é temático. Os levantamentos acompanhavam previsões como na "situação dos portos" ou "fechamento dos portos", que implica na privatização dos portos de Belém, das capitais da Amazônia. Como na situação de uma estrada, ou de um porto, de uma hidrovia, de uma base militar, de um aeroporto, nós estamos sempre acompanhando uma situação desse tipo em que os deslocamentos compulsórios de populações são colocados na primeira linha de implantação. Então esse aqui, esse primeiro ponto, são essas situações, digamos, que vão se sobrepondo e a gente vai trabalhando com isso. Estamos trabalhando com os fascículos, boletins informativos, com livros, já temos cerca de 27 livros publicados e sempre trabalhando do ponto de vista do grupo. Usando isso ao extremo, esse ponto de vista do grupo ao limite, isto é, repensando criticamente o trabalho etnográfico. 
João: Algumas coisas que eu anotei, professor, durante a sua fala pela manhã, na mesa, uma coisa que me chamou a atenção - claro que pelo espaço que teve na mesa, não foi possível você explorar, e acabou que as questões que foram colocadas na hora, foram para outro ponto. Mas eu gostaria que você pudesse retomar essa nova discussão que você trouxe de território. Você trouxe alguns aspectos, pensando Foucault (Território e Segurança); eu gostaria de saber, ainda nesta vertente que a gente pode pensar como pós-estruturalismo, a questão de território a partir do Deleuze e Guattari, se tem alguma ligação nisso também. Com essa nova semantização do termo.

Alfredo Wagner: Sim. Nós pensamos, inicialmente, João, em trabalhar com mapas situacionais. Nós sempre admitimos o seguinte: que essas identidades, elas são plurais. Diferentemente das concepções multiculturalistas das agências transnacionais. Uma pessoa, ela pode ser ao mesmo tempo, uma quebradeira, então participar do movimento das quebradeiras, uma mulher, quilombola, ela pode ter mais de uma identidade, ocupar várias posições ao mesmo tempo e ser do Sindicato dos Trabalhadores Rurais. Então, um mesmo agente social ocupa várias posições ao mesmo tempo. É claro que, em determinado momento, uma posição vai se sobrepor às outras e puxar as outras. Então o fato de ser quebradeira agora é importante, antes era marcado por estigma, não é? Então essa passagem de uma situação atomizada, de existência atomizada para uma de existência coletiva, é vinculada a uma instituição. Ela também é marcada pelas características das maneiras das pessoas se organizarem, em como as pessoas encaminham as suas reivindicações, e como elas estabelecem as interconexões com os poderes. Aqui começa a entrar o fulcro do mapeamento social. Porque cadastrar, mapear, identificar, delimitar, são todas formas, são todos termos do léxico burocrático, para definir uma situação, para guardar uma situação ou para delinear uma situação. Tanto que o cadastro é variado. Há um cadastro da pessoa, um cadastro do imóvel e um cadastro gráfico, que acompanha o imóvel. Então essa passagem de uma situação atomizada para uma situação coletiva, ela dá força ao grupo. E às vezes o resultado não é o que nós pretendíamos. Um paradoxo. Embora dê força ao grupo, o grupo pode acabar endossando 
tudo aquilo que é feito contra ele. Pode ocorrer isso. Esse também tem sido um drama para nós, porque nós ficamos numa situação meio delicada. No mais das vezes, entretanto, dá-se o inverso.

Os mapas que nós concebemos são mapas situacionais, ou seja, são mapas que podem mudar, variar sendo as transformações vividas pelos grupos e comunidades. Hoje eles têm uma configuração, amanhã podem ter outra. O que é que muda? O próprio embate que essas forças têm com outras forças externas, como o embate com grileiros, o embate com o Estado, o embate com grupos interessados na terra que querem usurpar ou adquirir. Então a mercantilização vai balizando esta delimitação, como é que ela pode ser estabelecida. A fronteira é um lugar de relações. A fronteira é o lugar onde o grupo se realiza com mais força identitária. Vejam aqueles 300 lá do caso de Esparta, onde o Leônidas vai enfrentar no desfiladeiro das Termópilas o rei Xerxes da Pérsia. Eles vão estabelecer uma fronteira, deste desfiladeiro eles não podem passar. Deste desfiladeiro não passam, porque se o fizerem tudo estará vivido como perdido irremediavelmente. Há um limite. Então fazse necessário você pensar os limites que estão nas cabeças das pessoas, que movem as pessoas, que as levam a cometer atos. Isto ali está muito claro. Mas, por exemplo, em países como Itália e Alemanha, que foram os últimos a se formarem na Europa, enquanto unidades, enquanto estado-nação, produzindo uma unificação tardia. A Itália era uma colcha de retalhos, a Itália de Turim distinguia-se daquela de Nápoles e esta da Sicília. Como é que se compõem isto? Há que ser construído com desvelo e com cautela. Identidade e território. Então, este é o atributo do mapeamento, ele é construído. É o atributo do construído, absolutamente construído. Para Barth também as cosmologias vão sendo construídas, tal como os territórios. Começamos a absorver algumas teorias da situacionalidade dos mapas. Não seguimos muito Deleuze e os "novos cartógrafos" ao falar de Foucault. Nós ficamos com autores que haviam produzido alguma crítica sobre as novas etnicidades. Nós procuramos trabalhar com conceitos que pudessem propiciar maior liberdade na compreensão dos atos de mobilização política. Procuramos trabalhar mais no sentido de Foucault. Levando em consideração o que é que estes autores estavam dizendo que era representação dos mapas. Ou o que era importante, no estudo 
etnográfico, você incorporar o mapa. O mapa é um dos elementos centrais da descrição. O mapa é o elemento fundamental para você subdividir, classificar, compor as partes que constituem o território. Isto, também, ficou logo claro, que ressaltou. Começamos a usar mapas situacionais, quer dizer, mapas que estão mudando o tempo todo. Também o número de pesquisadores do PNCSA aumentou muito, porque nós conseguimos, neste último projeto que mencionei para vocês, o número 4 , que é o projeto contra devastação e contra o desmatamento, apoiado pelo BNDES, somente neste trabalham 71 pesquisadores. Nos demais projetos temos outro tanto, num total de 90 e poucos pesquisadores. Então, também, começamos a fazer trabalhos em áreas inesperadas. Por exemplo, nos convidaram comunidades do Planalto Meridional, para a gente se aproximar, então mapeamos os faxinalenses, os povos dos Faxinais. Depois, as comunidades de fundo de pasto da Bahia também nos convidaram e nós começamos a fazer fascículos. Isto tudo vocês podem ver no nosso site, www. novacartografiasocial.com. Nós incorporamos comunidades fora da Amazônia, do Rio Grande do Sul, e de Santa Catarina com os quilombolas do Morro do Boi e pescadores da Costa da Lagoa. Agora estamos trabalhando em São Paulo, numa área protegida. Produzimos também na Bahia, no sertão da Bahia, às margem do São Francisco. Fizemos o livro, com Vania Fialho, sobre o assassinato de Chicão Xucuru. Só aqui seriam cinco estados que estamos trabalhando além dos nove da Amazônia. E ainda há outros colaboradores, como por exemplo, no Rio Grande do Norte, pesquisadores da Universidade Federal do Rio Grande do Norte, que são alguns que a gente já tem relações de parceria. Então aí daria um total de 16 ou 17 universidades, que são as universidades com as quais trabalhamos atualmente.

João: Durante a sua fala da manhã eu pensei um pouco nesta perspectiva que reflete a questão do território e segurança a partir das explicações do Foucault. A ideia seria pensar até que ponto não dá para considerarmos também essas ações de Estado, e então gostaria de saber mais sobre isto, do impedimento das titulações de terra, a questão quilombola (que é a parte que eu pesquiso), como a possibilidade de visualizarmos um estado de exceção. Se essa 
desmobilização por parte do Estado de não fazer as titulações, de recorrer ao que as comunidades exigem, o que as comunidades estão apresentando enquanto demanda, não seria uma forma também de estar criando, em certo sentido, um estado de exceção. No sentido de que é um perigo para o Estado que estas comunidades tenham suas demandas atendidas. Gostaria de saber qual seu entendimento em relação a isto.

Alfredo Wagner: $O$ território inicialmente estava sendo concebido como defesa nacional, naquela ideia do estado-nação. E agora nós começamos a reconhecer todos estes grupos emergentes: indígenas, quilombolas. Então isto já tinha uma certa diversidade em jogo. E utilizamos um conceito do antropólogo João Pacheco, "processo de territorialização". E começamos a trabalhar mostrando que estes são processos diferenciados de "territorialização", na verdade. E que cada um destes processos produz, tem como resultante uma territorialidade específica. Nós começamos a compor esta especificidade. Então começamos a trabalhar com a ideia de território, uma ideia de processo de territorialização, uma ideia de territorialidade específica, uma ideia própria de território como o elemento que organiza a passagem do processo de "territorialização" para o seu produto, que é a territorialidade específica. Nós cercamos de todos os lados e com este conjunto, que são instrumentos analíticos que nos ajudam a pensar situações empíricas. Não é que estas situações empíricas existam lá, mas esta maneira de definir os instrumentos nos ajuda a pensar estas relações empíricas. Foi isto que nos possibilitou, num primeiro momento, trabalhar com estas categorias. E nós vimos que os grupos se apropriavam muito facilmente do que lhes era transmitido em cada oficina de mapa, onde tínhamos feito os cursos antes. Então você administrava cursos de noções elementares de GPS, noção de o que é uma coordenada e o que é meridiano, o que é a Linha do Equador, o que é um Trópico de Câncer e Trópico de Capricórnio. Você começava a explicar para as pessoas essa situação, utilizando até um globo que ele ia passando e você ia explicando para as pessoas qual era a situação. Nós começamos, nas oficinas de mapa, a incorporar cursos rápidos. $\mathrm{E}$ começamos a ter produtos mais expressivos. Então conseguimos, desde 
2005 para cá, desses quase oito anos, 150 fascículos. Produzimos também boletins informativos, que são temáticos. Produzimos, também, um conjunto de livros. Temos mapas de várias situações, que são chamados mapas situacionais. Isto abriu caminho. Isto abriu bastante o caminho da reflexão, da possibilidade de análise. Incorporamos ainda o conceito de ambientalização trabalhado pelo antropólogo José Sergio Leite Lopes.

João: Você acha que estas ações do Estado em relação ao processo de territorialização...

Alfredo Wagner: É, no caso das ações do Estado hoje... no período de inspiração no neoliberalismo, o Estado começou a abrir mão da sua prerrogativa de mapear. O que o RADAM havia mapeado fica, o que a DSG havia mapeado fica, o que o IBGE havia mapeado fica. Não se avançou muito. Então nós começamos a não ter estes mapas, por exemplo, você perguntava sobre o mapa das terras públicas: não existe. O Estado desconhece o estoque de terras públicas. Onde estão as terras públicas na Amazônia? Você tinha a resposta: onde estão certos tipos minerais... Então hoje prepondera uma noção de Estado ligada a uma ideia de exploração, similar àquela do período militar, mas com uma ligação muito forte, como no caso do projeto Jari, no caso dos alemães no Carajás e dos japoneses e chineses no caso da exportação de commodities. Tudo com uma ligação muito forte com grandes conglomerados internacionais. Isto dominou um pouco a cena. Mas naquele momento estes grupos não estavam lutando para serem reconhecidos, eles estavam lutando por terra. Esta é uma diferença também muito grande.

Em 1989 você podia estudar com o conceito de Hobsbawm de "novos movimentos sociais". Ele nos bastava. Era um conceito que nos bastava. Dava para você trabalhar com ele. Entretanto, o que ocorre, já nos 2000 este conceito de "novos movimentos sociais" já estava sofrendo um bombardeio com o trabalho de Daniel Bensaid, de Sigmund Bauman, de Negri, de Zizek, de Laclau, de Anderson e de Badiou. Ou seja, todos que fazem a crítica a Hobsbawm. Que é que eles dizem? Olha, "novos movimento sociais", até esta ideia de adjetivo "novo", ela 
quer dizer insuficiência teórica e também dispersão. Ele não está definido, seria o reconhecimento de uma incapacidade teórica quando você coloca "novo". E os críticos completam: falta um programa, falta liderança, falta partido, falta objetivo maior que una todo mundo. Reconhecer a diversidade é insuficiente, significa autodefinir-se como "quebradeira", "seringueiro", "castanheiro", "pescador", "ribeirinho", "peconheiro", "piaçadeiros", "quilombola"... Dizem: não há um programa que una estas pessoas. Então não é um movimento social com características conhecidas, não teria dirigentes devidamente preparados, dizem. Esses são os senões. Além disto dizem: um movimento de dimensões modestas, que não está propondo tomar o poder. Está propondo ser multilocalizado. E é um movimento incapaz de profundas tranformações. É um movimento que junta agregados e temporários, sem perspectiva de continuidade. Então trata-se de um movimento meio que despolitizado, que fragmenta as forças. Então, esta é uma ideia que todavia persiste. A reconceituação de território vai também sofrer transformações nesta primeira década do século XXI, que é o que nós tentamos trazer para cá. E que é que esta via vai ter? Novos critérios de classificar as pessoas e as relações. Estes novos critérios, eles reacionam o quadro natural, reacionam os sistemas, porque antes era um biologismo acentuado. A partir do quadro natural, você definia o trabalho. Onde é que estão os seringueiros? Onde estão as castanheiras? Há sempre um trabalho de perguntar onde e quem é que classificou. Neste sentido, há uma crítica forte e estes movimentos não conseguem negar que não têm consciência de si mesmos. Não partilhamos desta convicção. Então os "novos movimentos sociais", na ideia do Hobsbawm, eram vínculos locais profundos, o critério de gênero, o critério étnicoracial etc. Problematizamos isto e refutamos os críticos abrindo possibilidades para uma redefinição das "novas etnias". Era mais uma situação de tentar produzir um mapeamento da sociodiversidade em movimento, em conflito. Se no inicio dos anos 1990 Hobsbawm nos traz esta teoria dos "novos movimentos sociais" apoiados nestes critérios, e agora? No fim dos anos 2009 e 2010 , começa a entrar o risco de outras associações em jogo. Outros personagens passam a estar presentes. Então quais são as outras? Você tem uma nova classificação dos grupos. Este é o desafio. Porque neste momento o caso da Amazônia, em 1989, 
- Banco Mundial cria o GTA (Grupo de Trabalho Amazônico), que chegou a ter 600 associações representando. E era um novo movimento social, só que isto perde a força de mobilização, perde a própria inspiração mobilizadora e aí vem o risco de outras associações e movimentos. Este risco começa a prevalecer hoje, 2009-2012. Estamos sob este risco de ter outros critérios de mobilização por serem estudados e compreendidos. Aqui está a nova cartografia social. Quais são estas novas fronteiras? Em primeiro lugar a emergência de novas expressões para designar espaços físicos: terra raras, cerrados, savanas. Pois tem uma redefinição de unidades de conservação. Isto é um dado relevante. Este reavivamento de algumas memórias, você começa a falar dos "indígenas isolados". E o que é que ocorre? Estes diferentes limites colocados às territorializações funcionam como elementos condicionantes da ação mineradora em terra indígena, da ação agropecuária em terra indígena, da ação das indústrias papeleiras em terra indígena. Então os índios, o isolamento passa a ser uma categoria presente, quer dizer, este Estado passa a se isolar para poder ter prerrogativa de sua autoridade. Então você tem novas fronteiras institucionais. Tem-se uma nova maneira de definir a Amazônia. Porque com a expansão dos agronegócios, eles querem parte do cerrado do Amazonas; querem parte do cerrado do Maranhão, donde estão plantando soja; e querem uma parte no Tocantins. Então aí vai ter um novo desenho geográfico, porque aí o mapa começa a ser redesenhado, começam a ter tensões para redesenhar os mapas. Ao mesmo tempo que todos os códigos começam a ser alterados também: código de processo civil, código florestal, código de mineração. Todos os códigos começam a ser alterados e ainda não temos uma visão acabada disto. Então isso aí vai provocando uma outra mudança, as pessoas como se fossem esgotando certos elementos identitários e fossem assumindo outros. Mas na verdade não é fadiga. É que não há efeitos. Há quantos anos que não se demarca a partir de um imóvel rural, que não se demarca uma área de quilombo? São muitos anos. O governo atual, até agora, só titulou uma área, apenas uma área e com condicionante. Você tem uma limitação desta ideia de território. E nós continuamos trabalhando com o projeto Nova Cartografia levando estes dados em consideração. Quais são os novos critérios então? Há novas formas 
organizativas? Se organizam como? Por laços de parentesco? Como as antigas unidades sociais? Não! Por afinidade política? Não, não tem a mesma visão. Mas se unem quando? Contra os inimigos circunstanciais. Então começamos a fazer este trabalho de indagação nos vários lugares, tanto que os mapas passaram a ser situacionais e toda a produção começou a ser de circunstância também. Então o Projeto Nova Cartografia Social vai nascer deste conjunto de reflexões, de indagações, que começamos a levantar dentro da Amazônia, nas universidades. E é assim que estamos pesquisando, trabalhando e produzindo mapas, num grande esforço etnográfico tal como aprendizes de um novo tempo. 